Military Technical College

Cairo, Egypt

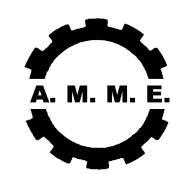

$12^{\text {th }}$ International Conference

on Applied Mechanics and

Mechanical Engineering (AMME)

\title{
DESIGN ALTERNATIVES FOR A MULTI-STANDARD MACHINE
}

\author{
Mohamed*M.A.S.
}

\section{ABSTRACT}

This paper puts forth a suggested concept to design a machine whose standardized parts belong to a variety of codes. Rewards of adopting such a multi-standard concept are discussed versus the drawbacks of the conventional single-standard concept. In order to overcome relevant huge computations, the study takes advantage of an artificial intelligence scheme called "uphill climbing" embedded with constrained permutations trials. The study ends up with three application findings. First, mixing of even a few standards yields a robust tangible reduction of machines' overall weight. Second, the more the number of mixed standards in a machine, the lighter is the machine's weight. Third, in the cases that both the machine's manufacturer and its user undergo some parts shortage, a set of reliable alternative designs become readily accessible.

*Arab Academy for Sciences and Technology, Egypt 


\section{BACKGROUND}

A common feature of machines is their assembly of numerous parts. Owing to national and economic norms, designers used to confine their machine parts so as to exclusively belong to a sole domestic standard. Practical evidences show that such a traditional, though non-compulsory, trend creates three drawbacks. First, in the design stage, parts selection is constrained by stepped tabulated values with remarkable increments in between. Basically, parts' stepped values and vacancies in standardized tables result from mass production requirements. Thus, in order to achieve his design goal such as light weight, low stress, high reliability, and long service life, a designer's need for a few extra millimeters might impose a vast shift to a higher standardized size (sometimes hundreds of millimeters more). Similar shifts imposed by all standardized parts housed in a prospective machine eventually build up to a shocking overall weight excess [1-3].

Second, abiding by the designer's instructions, a machine's assembler has to ensure continuous supply of all its parts. However, ordinary markets' ups-and-downs monopoly, boycott and bankruptcy of a single-standard parts' source, may unexpectedly make a certain part no longer available. In other words, if all parts are provided via a single-standard source, economic instabilities are likely to hinder continuous supply of either part. In such circumstances, an assembler faces two awful challenges. Either his business halts until modifying the part design towards an alternative standard. The delay might last while bringing all the machine details back to initial design stages allover again. Or, a prolonged shortage of that part will threaten both his assembly line and his assembled machine's continuity in markets [4 -6].

Third, a machine's routine maintenance entails incessant parts replacement by machine owners and users. Accordingly, lack of a machine's spare parts coming from a single-standard source or of information about their counterpart standards makes continuous possession of this whole machine worthless $[7,8]$.

Presented in this paper is a suggested concept calling for the construction of a machine from multi-standard parts. The idea is invoked by the fact that parts from diverse standards turned out to be readily available in global markets due to internetand communication-based supply $[9,10]$. In other words, removal of most traditional geographical barriers helped to willingly assemble a machine from parts, each belonging to a different standard. Easy accessibility of multi-standard parts will eventually enable a designer to not necessarily stick to a single standard to construct his prospective machine.

\section{THE MULTISTANDARD CONCEPT}

The proposed multi-standard assembly has a two-fold impact. First, a designer faces a broad hierarchy of parts from various standards with sequential valuesand less vacancies. Accordingly, there always exists a standardized size that closely fits his sought design value. This approach considerably reduces the selection inflexibility, design trials and overall machine weight. For instance, in conventional singlestandard concept, sizes of a certain part category are based on some constraints. Part sizes are tabulated in stepped discrete values, e.g. 13 then $15 \mathrm{~mm}$. A sought design value, such as 14 or $14.5 \mathrm{~mm}$, is then not stated in the adopted standard but 
may be available in other standards. Thus, incorporating such other standards allows a legitimate selection of the sought missing sizes.

Second, with multi-standard policy, machine assemblers and users will face minor challenges. To construct a machine assembly, the policy recommends to not relying wholly on one standard source. In other words, a standard source is permitted to supply just one or a few number of parts. Various standards sources are unlikely to fade away all at a given moment. Rather, if it happens, shortage will begin in only one part or one at a time. Thus, the worst case is only that simple case when a mere single part disappears in its standard source, whereas the remainder of machine parts is unaffected and still available, each in its own standard source. Since it is hard to expect which part might go first in shortage, the policy should be extended to cover all cases of probable unavailability of each single part in a given assembly. For whatever case that a part becomes missing, the designer's proposed hierarchical tables can prescribe a related alternative standard source. This makes the assembler's duty be drastically simplified. He smoothly and swiftly switches to the alternative version prescribed beforehand. Just a localized design modification based on the predetermined alternative standard helps him immediately resume part accessibility and persist his assembly in markets.

For instance, in car assembly industry, original design is carried out in a licenseholding country, whereas another country may undertake the assembly processes. Once production starts, cost factor implies that a percentage of sensitive parts come from the license-holding country, whereas the rest of parts is controversially managed from the nearly equivalents in the home market of the assemblymanufacturing country. Close observations show that many production-introduced modifications are saved when the early design stages adopt a multi-standard policy combining both countries' standards.

\section{PROBLEM FORMULATION AND OBJECTIVE}

Despites the aforementioned advantages, the proposed multi-standard concept still expectedly requires a rational mathematical assessment. Designers here are bound to face superfluous tabulated data and huge permutation trials, inevitably leading to laborious computations. For instance, a machine assembly with $n$ parts being supplied via $m$ standard sources, where $m>n$, is arbitrarily tabulated as $m$ columns (parts) $\mathrm{x} n$ rows (standard sources). Part weights in each row belong to one standard source and each column features one part if supplied from different standards. Thus, weights in each row display the parts of a machine as if wholly supplied by each single standard source. In the absence of whatever source constraints on any selected part, we have to search $\mathrm{m}^{\mathrm{n}}$ column permutation assembly trials in order to find out which combination of parts provides the machine's lightest weight.

\section{THE SEARCHING TECHNIQUE}

Although attainment of the minimum-weight goal seems time-consuming and errors' riser, a short and automated technique can be borrowed from artificial intelligence's similar topics. The uphill climbing technique (UHC) is often used to handle one set of tabulated column data as stations of compulsory subsequent jumps. Based on a series of leftward gradual shifts, the overall minimum of a contest is found as a sum 
of successive picking up of the minimum in all columns. Nevertheless, in our multistandard table, the goal of minimum weight is subject to the following additional constraints;

a) If $n>=m$; find the best $m$-standard set such that each selected standard source is permitted to supply only one part. In this case we fully rule out the rows of (n-m) standards, and keep $m$ standards with share of one part each.

b) If $n<m$; find the parts' standard such that all integer shares $(n / m)$ are equal or close, and decide which standards is preferred to provide slightly higher shares.

c) In the case that one standard is unable to provide its assigned part, rule its part out partially and determine which next column permutation is preferred.

Under such above constraints, each minimum value picked up in a given column part will affect the next selection by redefining another minimum of the remaining parts in the column considered. Since our columns' mutual positioning is arbitrary (being compulsory in UHC), these constraints provoke an extended searching over all column permutations. As a result, the number of tested trials drops from the original $\mathrm{m}^{\mathrm{n}}$ to only $\mathrm{n}$ ! trials. In addition, since many part's combinations are found to yield similar sum values, a limited set of randomly selected permutations, e.g. 100, are sufficient to pick up the optimum minimum sum.

\section{A REAL CASE STUDY}

The proposed technique is applied to a gearbox design with 7 standardized grouped parts. Each single group can be provided via 10 standards. Each standard source is ready to provide any share $(p)$ of the required groups, where $0 \leq p \leq 7$ grouped parts.

Table 1 shows the division of shares in the case of $n=10$ and $m=7$. In the trivial case of one standard source, this source has to provide all seven groups. In the case of two standard sources, we face the first question of shares division. Next, we face the question as to which source is preferred to provide four items whereas the other provides only three groups. There is still the question as to how to select the four groups with the lowest total weight. In the case of three standard sources, two sources provide groups more than the third source. Whose share is higher? Which source provides which group? The case of 7 suppliers providing one item each is trivial in terms of the question of share division. However, the question of group assignment still needs answering.

Data of a 5 -speed $20-\mathrm{Kw}$ gear box as design proposals are collected from 10 standard sources. Parts of each gearbox are sorted in seven groups, each having a known weight value as illustrated in Table 2. Statistical testing of tabulated data indicates that they follow a random law close to $\left(20^{*} \mathrm{j}+100+50{ }^{*} \mathrm{R}\right)$, where (j) is the column order and $(R)$ is probability from a uniform distribution. Overall weights are then summed up and design proposals are arranged in descending order, the heaviest proposal being at the table top as the DIN standard indicated by 10 . The designer now is free to select any set of ten different groups, from the ten columns, so that the assembled gearbox has a minimum weight. The following three cases show that mixing of standards always results in a noticeable weight reduction. 


\subsection{Case 1. Random Embedding of a Given Proposal}

Consider a random arrangement of the ten given standards such as $\{5,10,6,7,9,4,1,8,2,3\}$. Accordingly, we start by selecting all seven groups from only one arbitrary single-standard proposal, being here the single-standard partial set $\{5\}$, weighing $1412 \mathrm{~N}$. The next step is to construct the same gearbox by selecting the seven groups from a partialset of the two standards ordered from left, i.e. $\{5,10\}$. The number of groups assigned to each standard is based on the constrained division recommended in Table 1, being 4:3. Application of the suggested optimization technique yields a lower weight of $1388 \mathrm{~N}$. This process is then repeated with all partial sets of multiple standards, i.e. $\{5\},\{5,10\},\{5,10,6\},\{5,10,6,7\} \ldots$ following the considered random arrangement up to the tenth set encompassing all contributing standards. A plot of computation results is depicted in Fig.(1) to show the mixing effect of several standards on the gearbox overall weight. Any number (p) on the horizontal axis indicates the sum of contributing standards in a partial set of the considered random scheme. For instance, number (1) indicates a single-standard proposal including only the fifth BS standard, whose given weight is $1412 \mathrm{~N}$. Number (2) means the set $\{5,10\}$, with share division ratio $4: 3$. The third design is a threestandard set of standards $\{5,10,6\}$ with a share division ratio 3:2:2.

Based on seven construction groups, mathematical mixing of any multi-standard set provides $7 !=5040$ assembly designs, or equivalently, weights. However, similar weight values repeat remarkably. For a comprehensive illustration, both the best and worst weights are plotted for each set. Other weight values span the range between the two lines. In fact, this useful weight span provides all weight available once a set of standards is decided to replace an arbitrary single-standard proposal.

Examination of Fig.(1) reveals that standards mixing yields a best line of a general decreasing tendency below the lightest proposal. The more the sum of mixed standards the lighter is the multi-standard gearbox weight. At the full mixing of all ten standards, a considerable reduction of $8.64 \%$ of the initial proposal is achieved.

The worst line shows a similar decreasing tendency but with two distinct summits above the lightest proposal but still below the mean weight. The first summit, often located at the 7 -standard set i.e. $n=m=7$, stems from severe constraints imposed with no alternatives offered. In other words, the sought design has to include just one group from any of the only seven selected standards. Away from this specific set, constraints relief results in a relevant weight drop. The drop to its right is due to incorporating more standards with their extra various groups. The drop to its left is due to permitting any standard to offer a share of more than one group. In addition, the second summit, accidentally located here at the 5-standard set, often occurs somewhere because of constrained division limits of the 7 shares among a fewer number of standard.

\subsection{Case 2. Descending Embedding of the Heaviest Proposal}

Here we start with the heaviest proposal at the top row of table 1, being the singlestandard set $\{10\}$ weighing $1477 \mathrm{~N}$. This design proposal will be regularly embedded by the next lighter-standard rows from top to bottom. Thus, the ten sets are $\{10\}$, $\{10,9\},\{10,9,8\}, \ldots,\{10,9,8,7,6,5,4,3,2,1\}$. Fig.(2) illustrates the variation span of the resulting overall weight for the ten sets. Examination of the best line reveals a noticeable early achievement at the three-standard set whose weight soon drops to 
the lightest proposal level. Successive mixing with more standards ends with a final reduction of $12.66 \%$ of the heaviest proposal. The worst line has a similar decreasing trend. For few-standard sets it drops close to the best line, for meanstandard sets it pauses near the lightest proposal level, and for many-standard sets it drastically falls down.

\subsection{Case 3. Ascending Embedding of the Lightest Proposal}

Here we start with the lightest proposal at the bottom of Table 1, being the singlestandard set $\{1\}$ weighing $1399 \mathrm{~N}$. This design proposal will be regularly embedded by the next heavier standards rows from bottom to top. Thus, the ten sets are $\{1\}$, $\{1,2\},\{1,2,3\}, \ldots,\{1,2,3,4,5,6,7,8,9,10\}$ Fig.(3) illustrates the variation span of the resulting overall weight for the ten sets. Examination of the best line reveals a noticeable early achievement at the three-standard set whose weight soon drops far below the lightest proposal level. Successive mixing with more standards ends with a final reduction of $7.79 \%$ of the lightest proposal. The worst line has a similar decreasing trend. Although the profile has the two constraint-accumulation summits previously described in case 1 , both extreme valuesstill lie below the lightest proposal level. Fig.(3) tells an important finding regarding the mixing concept. We know that the typical design methodology used to abide by a single-standard based on the wrong belief that it imparts the lightest best weight. Nevertheless, the present case shows that embedding of the lightest proposal with the groups borrowed from another even heavier standard yields a lower overall weight. Despite numerous combinations, the embedding process ends definitely with replacing some heavier groups by lighter counterpart groups from the extra standard.

\section{DISCUSSION}

As shown in Figs.(1-3), depending on the starting proposal, the weight reduction profile varies and may drop to $12 \%$. However, with the tenth set of full mixing, the optimum design is unique and weighs $1290 \mathrm{~N}$ independent of the chosen mixing scheme. This optimum combination design is marked by (1) in the cells of Table 3. Referring to the corresponding cells in Table 2 helps in expressing the weights of selected groups and finding the overall weight of the mixed gearbox. Notice that this design picks up only seven standards and rules out three standards, being $\{5,9,10\}$. Assume that we convincingly advocate the ten-standard mixing as a new design concept but for some practical problems the seven groups of the indicated optimum mixed design are not readily available. The optimization technique can still be extended to provide a second optimum substitute with a new combination of other seven groups while three other standards ruled out. This is done by emptying the cells of design substitute (1) and reapplying the searching technique. The groups of the second optimum substitute are marked by (2) in the cells of Table 3 and their corresponding weights are found in corresponding cells of Table 2 . It should be recalled that the design substitute 2 is optimum provided that optimum design 1 is out of stock. Similarly we can find optimum substitute 3 constrained by the unavailability of optimum design substitutes 1 and 2. As a result of constraints accumulation, weights of optimum design substitutes increase as shown in Fig.(4). Notice that the worst line is informative only and refers to the ceiling values of combinations span at each substitute. 
Fig.(4) presents four independent substitutes all below the lightest proposal level. If these four substitutes are all out of stock, the designer faces two choices. Either he switch to the lightest proposal or to use substitutes 5 and 6 , being still below the heaviest proposal level. In the case of unavailability of up to the sixth substitute, a tradeoff or a compromise should be practiced either to use the heaviest proposal or to use either one of $\{7,8,9,10\}$ substitutes depending on which criterion, low weight and multiple standards, is preferred. In Table 3, notice that only the highly constrained optimum design, i.e. the tenth substitute, violates the rule of single-group from single-standard. This expected violation results from the effect of original numeric data on the last set of compulsory nonempty cells. Two typical practical constraints can be similarly analyzed. First, if a standard source is run out of business, it is omitted from the selection table and all its groups are cancelled. Second, if a selected standard source is run out of his assigned groups, the missing groups are selected from the next appropriate standard source. However, the previous standard source is still considered in the selection table for its remaining group.

\section{CONCLUSION}

This study presents a weight analysis when a machine is constructed from parts of various standards. Practical observations show that this concept is already underway in today's automotive industry and maintenance, Just to name a few. During the early design stage, a noticeable drop in weight occurs in two cases. Either when not all group minimums belong to a unique standard or when more than one standard source provides a specific group with an identical weight value. As far as assembler and user are concerned, the suggested analysis helps add a reliability feature to assembly designs. This reliability feature is best assessed in terms of risk analysis. If all parts of an assembly belong to a single standard, the simplest probability of the absence of one item has a catastrophic impact in the form of full halt of an assembly industry (risky). The reason is that the standard loses confidence and stability in markets. Even if the missing part is successfully replaced by an alternative standard, the vulnerable standard is likely to cause another different part to hide. Conventionally, a strange part is hard to match a collection of inflexible similarstandard parts. On the other hand, if each part of an assembly is designed within the theme of different standards, the simplest probability of the absence of one item has a slight impact on an assembly industry, since availability of many other permutations ensure the existence of a set of good alternatives (risk-free). Traditionally, a single strange part is easy to match a collection of dissimilar-standard parts.

\section{REFERENCES}

[1] A. Shanian and O. Savadogo, A material selection model based on the concept of multiple attribute decision making, Materials \& Design, Volume 27, Issue 4 in press, (2006), pp 329-337.

[2] M.J. Matos and M.H. Simplício, Innovation and sustainability in mechanical design through materials selection, Materials \& Design, Volume 27, Issue 1 in press, (2006), pp 74-78. 
[3] Feng Zhu, Ke-Zhang Chen and Xin-An Feng, Development of a CAD modeling system for components made of multi heterogeneous materials, Materials \& Design, Volume 26, Issue 2 , April (2005), pp 113-126.

[4] F. Giudice, G. La Rosa and A. Risitano, Materials selection in the Life-Cycle Design process: a method to integrate mechanical and environmental performances in optimal choice Materials \& Design, Volume 26, Issue 1, February (2005), pp 9-20

[5] Bruno Scherrer, Asynchronous neurocomputing for optimal control and reinforcement learning with large state spaces, Neurocomputing New Aspects in Neurocomputing: 11th European Symposium on Artificial Neural Networks, Volume 63 , January (2005), pp 229-251.

[6] K.L. Edwards, Selecting materials for optimum use in engineering components, Materials \& Design, Volume 26, Issue 5 , August (2005), Pages 469-473.

[7] W. F. Lu and Y. -M. Deng, A system modelling methodology for materials and engineering systems design integration, Materials \& Design, Volume 25, Issue 6 , September (2004), pp 459-469.

[8] A. M. K. Esawi and M. F. Ashby, Computer based selection of joining processes, Methods, software and case studies, Materials \& Design, Volume 25, Issue 7 , October (2004), pp 555-564

[9] Natalia S. Ermolaeva, Maria B. G. Castro and Prabhu V. Kandachar, Materials selection for an automotive structure by integrating structural optimization with environmental impact assessment, Materials \& Design, Volume 25, Issue 8 , December (2004), pp 689-698.

[10] Srikanth K. Iyer and Barkha Saxena, Improved genetic algorithm for the permutation flowshop scheduling problem, Computers \& Operations Research, Volume 31, Issue 4 , April (2004), pp 593-606

Table 1 Division of Shares of individual contributing standards

\begin{tabular}{|c|c|c|c|c|c|c|c|c|c|c|}
\hline No of standards $n$ & 1 & 2 & 3 & 4 & 5 & 6 & 7 & 8 & 9 & 10 \\
\hline $\begin{array}{l}\text { Ruled out\& backup } \\
=0 \quad \text { if } n \leq m \\
=n-m \quad \text { if } n>m\end{array}$ & 0 & 0 & 0 & 0 & 0 & 0 & 0 & 1 & 2 & 3 \\
\hline \multirow{7}{*}{$\begin{array}{l}\text { Number of Shares } p \text { per } \\
\text { each standard, } \\
0 \leq p \leq 7\end{array}$} & 7 & 4 & 3 & 2 & 2 & 2 & 1 & 1 & 1 & 1 \\
\hline & & 3 & 2 & 2 & 2 & 1 & 1 & 1 & 1 & 1 \\
\hline & & & 2 & 2 & 1 & 1 & 1 & 1 & 1 & 1 \\
\hline & & & & 1 & 1 & 1 & 1 & 1 & 1 & 1 \\
\hline & & & & & 1 & 1 & 1 & 1 & 1 & 1 \\
\hline & & & & & & 1 & 1 & 1 & 1 & 1 \\
\hline & & & & & & & 1 & 1 & 1 & 1 \\
\hline $\begin{array}{l}\text { Q1? standard selection \& } \\
\text { share number }\end{array}$ & - & \multicolumn{5}{|c|}{$\begin{array}{l}\text { Whose share is higher? } \\
\text { Division ratio }\end{array}$} & - & \multicolumn{3}{|c|}{$\begin{array}{l}\text { Which standards } \\
\text { are selected? }\end{array}$} \\
\hline Q2? Items assignment & - & \multicolumn{9}{|c|}{ Which standard provides which group? } \\
\hline
\end{tabular}


Table 2 data of ten single-standard proposals of a gearbox

\begin{tabular}{|c|c|c|c|c|c|c|c|c|c|}
\hline \multirow[t]{2}{*}{ standard } & \multicolumn{7}{|c|}{ Items } & \multirow[b]{2}{*}{$\begin{array}{l}\text { Overall } \\
\text { weight }\end{array}$} & \multirow[b]{2}{*}{ order } \\
\hline & $\begin{array}{l}\text { FEAT } \\
\text { HERS }\end{array}$ & $\begin{array}{c}\text { BOLT } \\
\mathrm{S}\end{array}$ & $\begin{array}{c}\text { ACCES } \\
\text { S- } \\
\text { ORIES }\end{array}$ & $\begin{array}{l}\text { BEAR- } \\
\text { INGS }\end{array}$ & $\begin{array}{l}\text { SHAF } \\
\text { TS }\end{array}$ & $\begin{array}{c}\text { GEA } \\
\text { RS }\end{array}$ & $\begin{array}{c}\text { CASI } \\
\text { NG }\end{array}$ & & \\
\hline DIN & 147 & 161 & 198 & 221 & 250 & 239 & 261 & 1477 & 10 \\
\hline CSN & 135 & 159 & 183 & 226 & 229 & 269 & 272 & 1472 & 9 \\
\hline GOST & 158 & 143 & 192 & 229 & 240 & 228 & 269 & 1459 & 8 \\
\hline ASTM & 134 & 180 & 190 & 229 & 201 & 267 & 256 & 1457 & 7 \\
\hline IS & 149 & 183 & 163 & 209 & 234 & 235 & 276 & 1449 & 6 \\
\hline BRITISH & 155 & 158 & 174 & 207 & 202 & 252 & 263 & 1412 & 5 \\
\hline POLAND & 159 & 188 & 175 & 191 & 205 & 240 & 250 & 1409 & 4 \\
\hline ITALY & 155 & 142 & 186 & 221 & 205 & 235 & 261 & 1406 & 3 \\
\hline CHINEESE & 161 & 187 & 173 & 192 & 214 & 228 & 244 & 1400 & 2 \\
\hline JAPAN & 121 & 184 & 191 & 215 & 205 & 234 & 249 & 1399 & 1 \\
\hline
\end{tabular}

Table 3 The ten optimum substitutes

\begin{tabular}{|c|c|c|c|c|c|c|c|}
\hline \multirow{2}{*}{ standards } & \multicolumn{7}{|c|}{ parts } \\
\cline { 2 - 9 } & FEATHERS & BOLTS & $\begin{array}{l}\text { ACCESS- } \\
\text { ORIES }\end{array}$ & $\begin{array}{l}\text { BEAR- } \\
\text { INGS }\end{array}$ & $\begin{array}{l}\text { SHAF- } \\
\text { TS }\end{array}$ & $\begin{array}{l}\text { GEA- } \\
\text { RS }\end{array}$ & CASING \\
\hline DIN & 4 & 3 & 10 & 6 & 10 & 7 & 5 \\
\hline CSN & 3 & 4 & 5 & 9 & 7 & 10 & 8 \\
\hline GOST & 6 & 2 & 8 & 7 & 9 & 1 & 10 \\
\hline ASTM & 2 & 6 & 7 & 10 & 1 & 9 & 4 \\
\hline IS & 5 & 7 & 1 & 3 & 8 & 6 & 9 \\
\hline BRITISH & 7 & 5 & 3 & 4 & 2 & 8 & 6 \\
\hline POLAND & 8 & 10 & 2 & 1 & 4 & 5 & 3 \\
\hline ITALY & 9 & 1 & 6 & 8 & 5 & 2 & 7 \\
\hline CHINEESE & 10 & 9 & 4 & 2 & 6 & 3 & 1 \\
\hline JAPAN & 1 & 8 & 9 & 5 & 3 & 4 & 2 \\
\hline
\end{tabular}




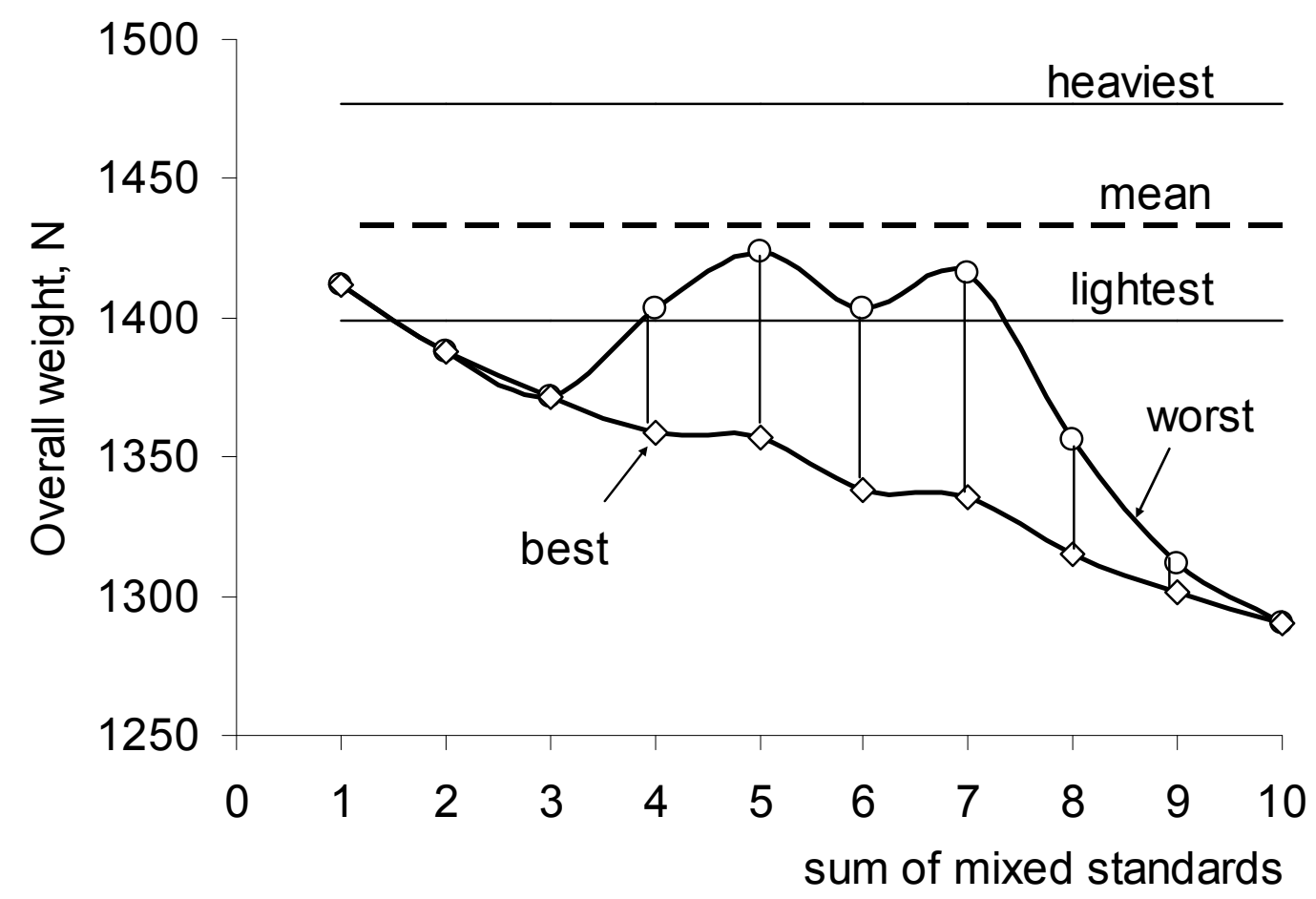

Fig.(1) Modification span of overall weights due to arbitrary mixing

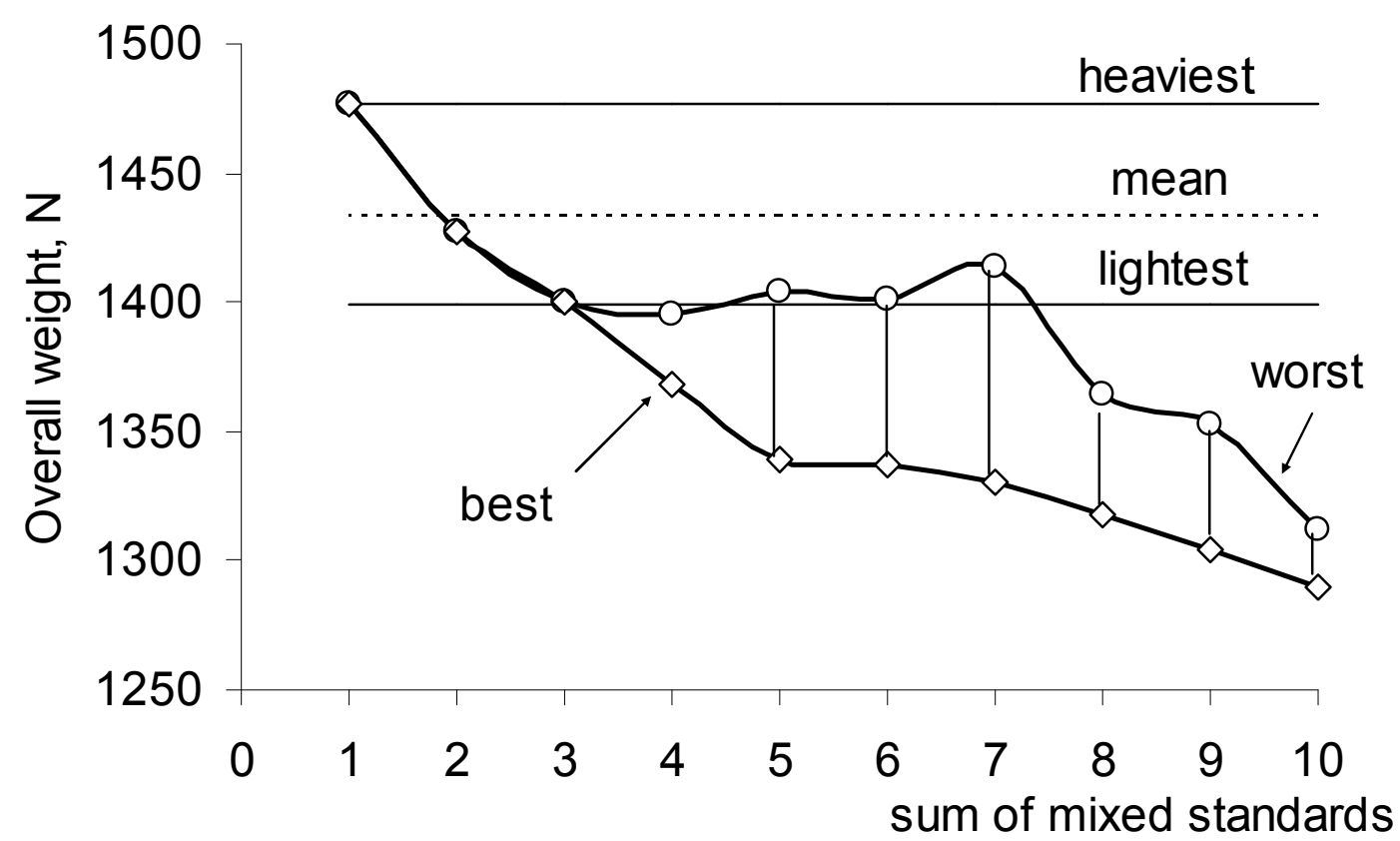

Fig.(2) Modification span of overall weight due to mixing to the next lighter standard 


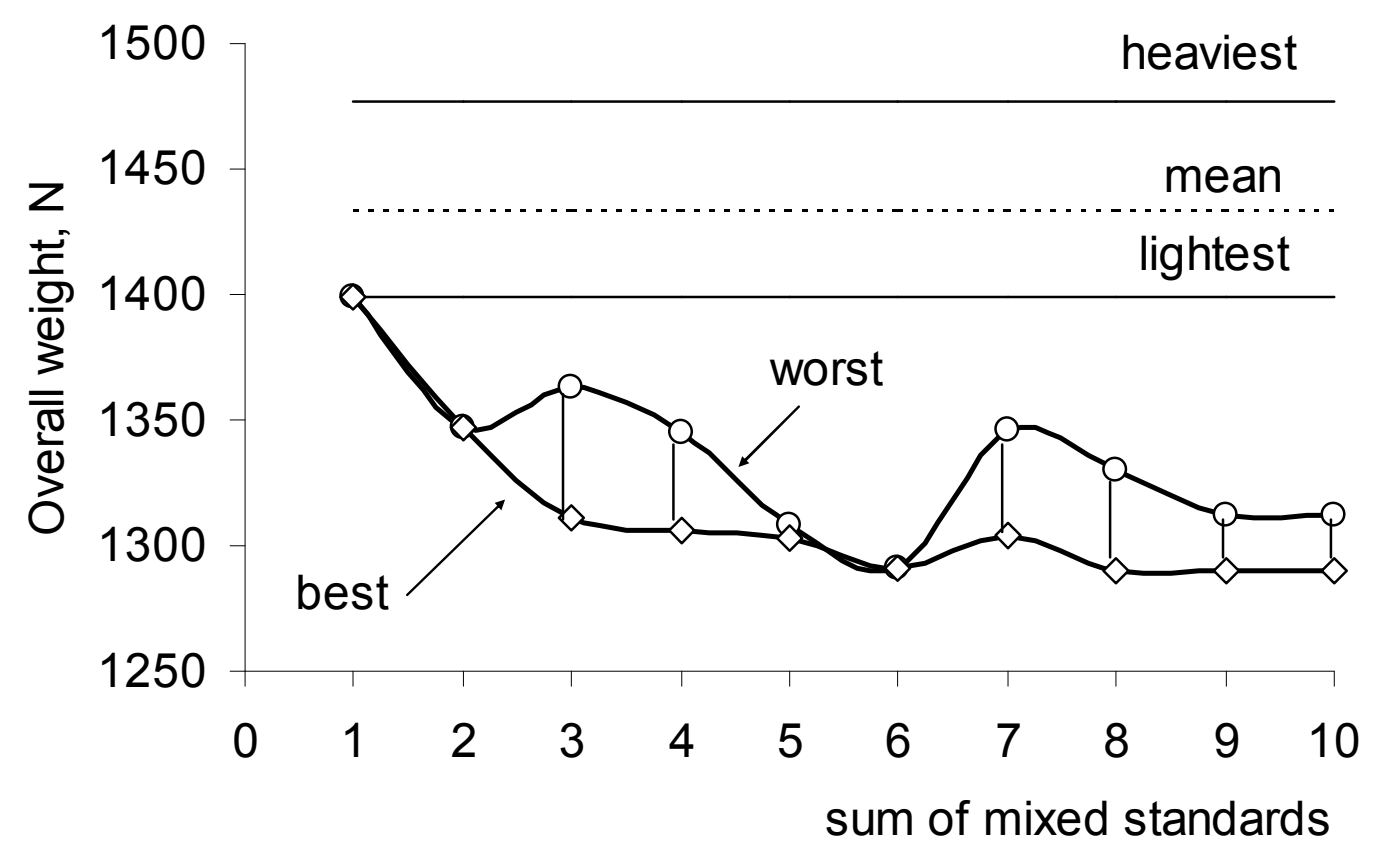

Fig.(3) Modification span of overall weight due to mixing to the next heavier standard

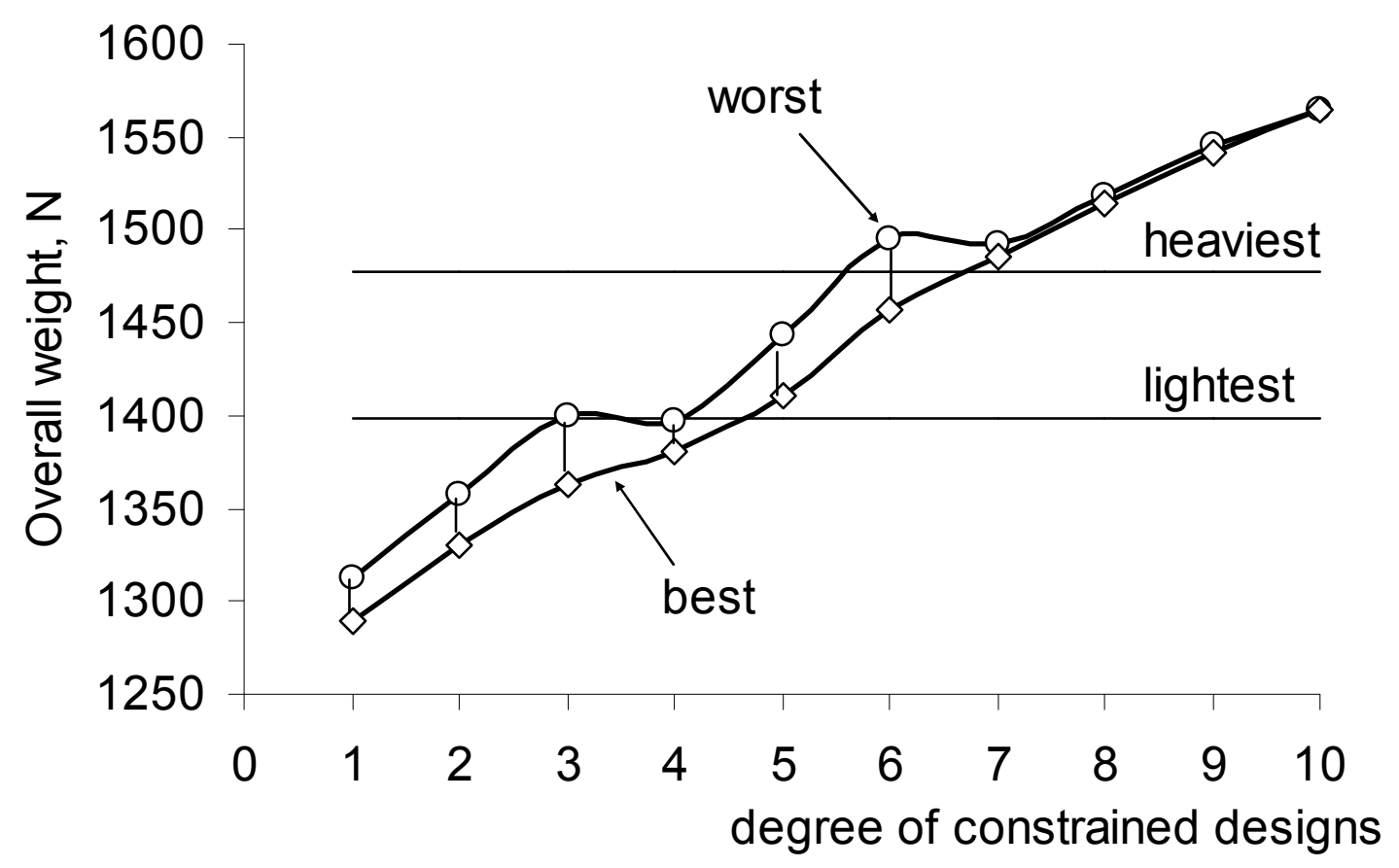

Fig.(4) Modifications span of overall weight for optimum substitues when some selected groups are missing 